\title{
EL VIAJE HACIA LA ANTIGÜEDAD EN EL SUEÑO DE POLIFILO DE FRANCESCO COLONNA (VENECIA, 1499)
}

\author{
Mariana Sverlij \\ Universidad de Buenos Aires-CONICET
}

Data recepción: 2018/12/12

Data aceptación: 2019/05/23

Contacto autora: msverlij@filo.uba.ar

ORCID: https://orcid.org/0000-0002-6357-5296

\section{RESUMEN}

En la Hypnerotomachia Poliphili (Venecia, 1499), Polifilo recorre, en sueños, distintos espacios caracterizados por la presencia de culturas pretéritas representadas, fundamentalmente, a partir de sus lenguas y de sus creaciones arquitectónicas. De allí que su recorrido onírico pueda pensarse como un viaje hacia la Antigüedad. En el presente trabajo, indagamos en las peculiaridades de esta elaboración del mundo antiguo que, en los albores del siglo XVI, ofrece el libro de Colonna. Seguiremos para ello tres modos en que el texto y los grabados representan la Antigüedad: como (1) ruina, (2) como sueño (3) y como espacio híbrido.

Palabras clave: ruinas, sueño, antigüedad, Polifilo

\section{ABSTRACT}

In Hypnerotomachia Poliphili (Venice, 1499), Poliphilus visits, in his dreams, a series of spaces characterised by the presence of past cultures and essentially depicted through their languages and architectural creations. His oneiric voyage can thus be thought of as a journey towards antiquity. In this paper, we look into the specifics of the recreation of the Ancient world that is offered by Colonna's book at the dawn of the 16th century. We will consider three ways in which the text and the engravings depict antiquity: as a ruin (1), as a dream (2), and as a hybrid space (3).

Keywords: ruins, dreams, antiquity, Poliphilus

El anhelo de "volver a la antigüedad" se ha presentado como una de las premisas del llamado Renacimiento europeo. Este anhelo viene acompañado, ya desde Petrarca, de la conciencia de la distancia que separa el tiempo presente del tiempo antiguo. En términos de T. Greene:

Petrarca precipitó su propia crisis creativa porque realizó una serie de descubrimientos simultáneos que sólo se habian hecho fragmentariamente antes. Él fue quien descubrió cuán radicalmente se diferenciaba la Antigüedad clásica de la era cristiana; también vio con más claridad que sus predecesores cómo los rasgos particulares de una sociedad determinada en un determinado momento forman una constelación característica, y comprendió más claramente el sentido filológico del anacronismo...'

De un modo diverso, en la Hypnerotomachia Poliphili (Venecia, 1499), ${ }^{2}$ atribuida al fraile véneto F. Colonna, ${ }^{3}$ no hay sentido del anacronismo: lo antiguo y lo moderno vuelven a aproximarse. Aún más: la antigüedad -que recrea la narración y la serie de 171 xilografías ${ }^{4}$ a ella asociadas-adquiere la fisonomía de un sueño.

En efecto, la Hypnerotomachia Poliphili (Lucha de amor en sueños de Polifilo o Sueño de Polifilo) 


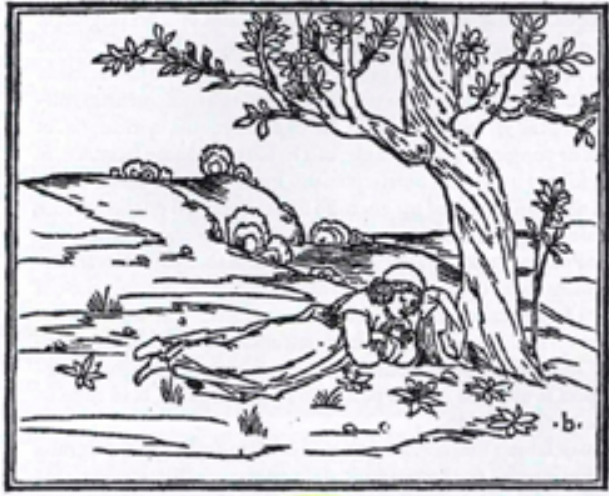

Fig. 1. El sueño de Polifilo. Grabado de la edición aldina, Hypnerotomachia Poliphili, 1499. Tomado de Francesco Colonna, Hypnerotomachia Poliphili, a cura di Marco Ariani e Mino Gabriele. Tomo primo: riproduzione dell'edizione aldina del 1499 (Milano: Adelphi, 1998), 20

consta de dos libros que relatan un sueño que acontece dentro de otro sueño. En este marco onírico, por un lado, Polifilo inicia la búsqueda de su amada Polia. Hallada Polia, los amantes inician un viaje conjunto, de reencuentro, celebración y consagración del Amor. Por otro lado, Polifilo recorre en su sueño distintos espacios caracterizados por la presencia de culturas pretéritas representadas, fundamentalmente, a partir de sus lenguas y de sus creaciones arquitectónicas. De allí que su recorrido onírico pueda pensarse como un viaje hacia la antigüedad.

En el presente trabajo, indagaremos en las peculiaridades de este viaje a la antigüedad que, en los albores del siglo XVI, ofrece el libro de Colonna en el plano del texto y de las imágenes. Seguiremos para ello tres modos en que el texto y los grabados representan la antigüedad: como (1) ruina, (2) como sueño (3) y como espacio híbrido.

\section{Las ruinas}

El primer encuentro de Polifilo con el mundo antiguo es a través de la percepción de un imaginario cuya totalidad perteneció a otro tiempo y del que sólo han quedado un cúmulo de ruinas. Apenas iniciado su recorrido onírico, Polifilo vislumbra a lo lejos una gran construcción

que semejaba obra y estructura antigua ... me detuve a mirar y considerar todo el volumen y el grosor de

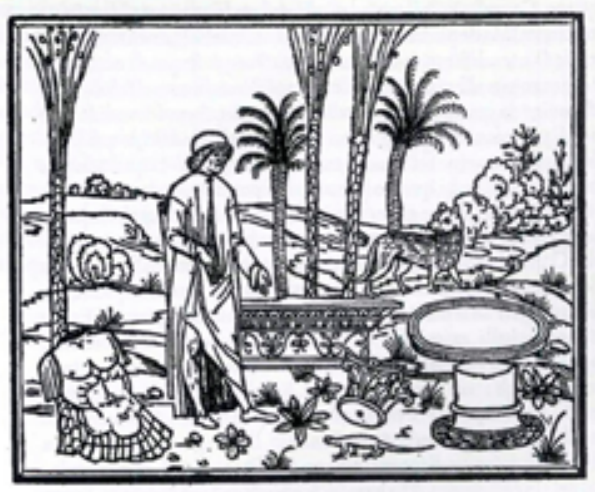

Fig. 2. Polifilo entre ruinas. Grabado de la edición aldina de 1499, Hypnerotomachia Poliphili, 21

esta fragmentada y medio destruida estructura... Alli encontré columnas tan nobles, de toda clase de formas...grandes fragmentos de estatuas privadas de los broncíneos y perfectos miembros. Y otros casi infinitos fragmentos de noble escultura, cuyo primitivo estado era prácticamente imposible de reconstruir en su integridad, casi reducidos como estaban a su materia primitiva apenas desbastada, caídos y esparcidos por el suelo aquí y allá. ${ }^{5}$

Como aquí podemos observar, una de las formas en que encuentra expresión la antigüedad, en el Sueño de Polifilo, es a través de sus restos. El texto de Colonna en este sentido puede ubicarse dentro de una constelación de producciones humanistas del siglo XV en donde la ruina ocupa un lugar central, empezando por una de sus fuentes principales: el tratado de arquitectura de Leon Battista Alberti, De re aedificatoria, publicado póstumamente, en 1485. En De re aedificatoria, la ruina se presenta como uno de los motores que llevan a Alberti a emprender la escritura de la obra. Disgustado por el estado de los edificios antiguos, incita a aprender de ellos "como si de profesores se tratara":

Sobrevivían aún ejemplos de antiguas obras, como teatros y templos, de los que, como de insignes profesores, sería posible aprender mucho: veía, no sin lágrimas en los ojos, cómo iban siendo destruidos día a día; y que quienes, acaso, llevaban a cabo una construcción contemporáneamente, se inspiraban más en tonterías y extravagancias de moda, que en seguir los criterios ya ampliamente probados en las obras más elogiadas; por todo lo cual, nadie negaba 
que, en breve tiempo, esta, por así decir, parte de la vida y del conocimiento, habría, seguramente, desaparecido del todo. Siendo ésta la situación, no podía sino ponerme a meditar con gran frecuencia y durante largo tiempo, sobre la posibilidad de comentar estos temas. ${ }^{6}$

Las ruinas de la antigüedad, de este modo, aparecen en el tratado albertiano como un modelo vivo, que no sólo provoca una mirada melancólica sino que invita a una acción reparadora.

La consideración histórica de las ruinas, de acuerdo con Burke, empieza con Petrarca: "Al contrario que los autores medievales, Petrarca no daba por supuestas las ruinas de Roma. Fue el primer anticuario moderno, en el sentido de alguien a quien interesa la reconstrucción del pasado a través de sus restos físicos". . Una generación más tarde, Poggio Bracciolini (1380- 1459) se ubica en las ruinas romanas para reflexionar sobre la inconstancia de la fortuna (De varietate Fortunae), mientras que Flavio Biondo (1388- 1463) proyecta la reconstrucción de estas ruinas en su Roma restaurata, escrita entre 1440 y 1446.

La obra de Colonna, a pesar de tomar como fuente, junto con Vitruvio, el tratado de arquitectura albertiano para sus largas descripciones arquitectónicas, deja de lado la perspectiva histórico- arqueológica. En esta dirección, ha señalado Blunt que, lejos de la pasión arqueológica del temprano 400 florentino, el aspecto más destacado de la obra es su aproximación romántica a la antigüedad.8 Por lo pronto, en la Hypnerotomachia, los restos del mundo antiguo aparecen rodeados de elementos que remiten a otros horizontes culturales y temporales, modificando y multiplicando sus sentidos originales. En el marco de su sueño, Polifilo vuelve a dormirse. El grabado de Polifilo durmiendo (fig. 1), es seguido por otro que lo ubica en un espacio en ruinas que remiten al mundo antiguo (fig. 2). Detengámonos un momento en él. En esta xilografía destaca la naturaleza avanzando sobre los trozos del mundo antiguo y delatando la intrusión del presente "vivo". Dos personajes observan esta "intrusión": Polifilo, cuyas ropas raídas contrastan con una armadura de guerrero apoyada sobre un árbol, y una loba que remite a la Divina Comedia de Dante. La armadura se halla en directa relación con la "lucha de amor en sueños" que

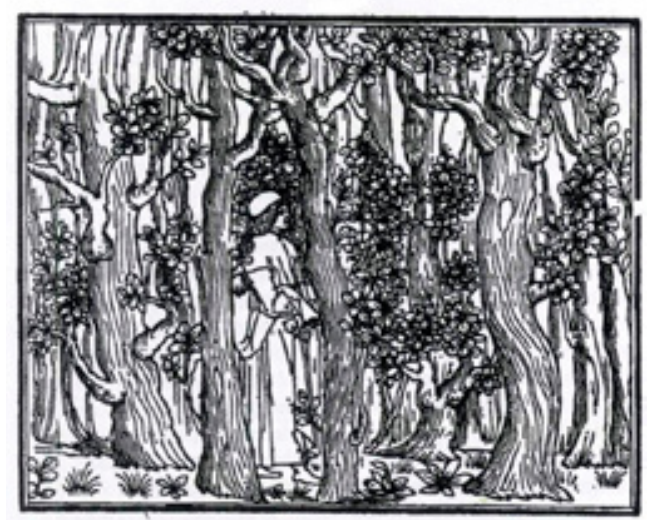

Fig. 3. Polifilo en la selva oscura. Grabado de la edición aldina de 1499, Hypnerotomachia Poliphili, 14

tendrá que emprender el peregrino en el viaje que está por iniciar. La loba, por su parte, dialoga con el primer grabado de Polifilo vagando en una selva oscura, también de reminiscencia dantesca (fig. 3). El entorno vegetal expresa, finalmente, las posibilidades de atravesar con éxito el camino que el peregrino está por emprender, a través de dos palmeras ("símbolo elegido para representar la victoria"): "aquí se presentó a mis ojos un alegre palmeral, con las hojas apuntadas y lanceoladas de tanta utilidad para los egipcios". ${ }^{9}$ El grabado, pues, se compone sobre la base de una mixtura cultural y espacio temporal, que se repite en el texto y en los grabados sucesivos. El mundo antiguo, presentado en su condición fragmentaria, podríamos decir, "se completa" con voces y tradiciones que remiten a un mundo más cercano.

En la obra de Colonna, la ruina expresa también la mutabilidad y fugacidad de las cosas humanas, erigiéndose, en forma simultánea, como un objeto digno de contemplación en sí mismo.

En el primer caso, la ruina-que delata el efecto del tiempo sobre el espacio- aparece en el Sueño de Polifilo como una forma apta para presentar historias desdichadas, con las que naturalmente entra en comunión. Este es el caso del Polyandrion, el cementerio donde yacen los amantes infelices, los muertos por amor. El cementerio mismo se erige sobre la base de esta redundancia: su estado fragmentario es el escenario de la lectura de epitafios sobre historias de amores 
truncos. Esta proliferación de escenas de destrucción, por su parte, contrasta con el reencuentro amoroso de Polifilo con Polia. El peregrino, que se ha dormido perturbado por la carencia de su amada, en la mitad de su peregrinación onírica, logra encontrarla. Lo que estaba disperso -y cuya dispersión funcionaba como motor de la obra- se ha juntado: el ambiente que rodea a la pareja acompaña esta reunión, presentando una escena con carácter de oxímoron: "Así que la insigne Polia y yo, llenos de inmensa ternura y robustecidos en nuestro sincero amor... Ilegamos alegres, festivos y contentos a un edificio antiquísimo... arrojado al húmedo suelo por el tiempo voraz, la vejez corruptora y la negligencia". ${ }^{10}$

Este doble rostro de los acontecimientos aparece en el viaje de Polifilo por los restos de la antigüedad, advirtiendo sobre el carácter inestable y fugaz de las cosas humanas. Es lícito, en este sentido, trazar un posible recorrido para las xilografías que siguen a la de Polifilo rodeado de ruinas (fig. 2): Polifilo se encuentra en seguida con una mole arquitectónica (fig. 4), coronada por un obelisco sobre cuyo extremo gira, precisamente, una estatua alada de la Fortuna. Esta Fortuna -que personifica el carácter mudable de las cosas humanas-11 dialoga con el siguiente grabado donde unos amorcillos van cayendo del lomo de una estatua ecuestre. En la xilografía siguiente se aprecian, finalmente, "algunas figuras de hombres y muchachas danzando, cada uno con dos rostros: el de delante risueño y el posterior llorando (...). Bajo esta figura oval vi escrita la siguiente palabra: Tempus". ${ }^{12}$ (fig. 5).

La ruina, finalmente, se presenta como un objeto de veneración en sí mismo, en tanto fragmenti nobili que han resistido el paso del tiempo. Polifilo es invitado a contemplar estos fragmentos para su solaz (a tuo solacio mirare) por su amada Polia, que reconoce su amor por las obras antiguas:

Polifilo amadísimo, no ignoro que te agrada mucho ver las obras antiguas. Así que, mientras esperamos al señor Cupido, puedes ir entretanto tranquila y libremente a contemplar ese templo desierto, derruido por la vejez voraz y destructora (...) y admirar para tu solaz los nobles fragmentos que quedan, que son dignos de veneración. ${ }^{13}$
Si, como señala Mortier, "Poggio no oculta la fascinación que las ruinas ejercen sobre él, pero se trata de una fascinación erudita, arqueológica, y no de una incitación a la creación literaria" y "Biondo, y luego de él Leon Battista Alberti prefieren a la contemplación nostálgica de una antigüedad mutilada, el placer de la reconstrucción ideal de una Roma restaurada en su esplendor primero", ${ }^{14}$ la ruina en la obra de Colonna tiene valor en sí misma (en tanto proporciona placer, solaz), presentándose al mismo tiempo como síntoma de una carencia. Esta carencia expresa el carácter fugaz de los emprendimientos humanos dando lugar también al ensamblaje de elementos heterogéneos, a la creación de una nueva antigüedad.

\section{La Antigüedad como sueño}

Polifilo accede al mundo antiguo, quitándole su estatuto histórico. Y es que -como señala Sinesio de Cirene- "nada es tan propio de los sueños como sustraerse a las leyes del espacio y no obrar bajo las coordenadas del tiempo". ${ }^{15}$ Proponemos pensar, por consiguiente, en este aparatado, la recepción de la antigüedad en el marco onírico ofrecido por la Hypnerotomachia Poliphili. ${ }^{16}$

En su Comentario al Sueño de Escipción de Cicerón, Macrobio distingue cinco variedades principales de sueños, remitiéndose a los antiguos, "pues los antiguos han definido y regulado la profusión de imágenes que confusamente nos invaden mientras dormimos". ${ }^{17}$ En sus términos latinos, estas son el somnium (sueño enigmático), la visio (visión profética), el oraculum (sueño oracular), el insomnium (ensueño) y el visum (aparición). En esta clasificación, el sueño oracular (oraculum), la visión profética (visio), y el sueño propiamente dicho (somnium) son aquellos que tienen una proyección en el futuro. Particularmente, la visión (visio) anuncia lo que sucederá tal cual había aparecido en sueños, en cambio el somnium "oculta con símbolos y vela con enigmas la significación incomprensible sin interpretación de aquello que muestra" ${ }^{18}$ Para Sinesio de Cirene el género de sueños más común y frecuente es el enigmático, al que es necesario aplicar el arte interpretativo. ${ }^{19}$

Como sucede en el Sueño de Escipión relatado por Cicerón en su República, la Hypneroto- 


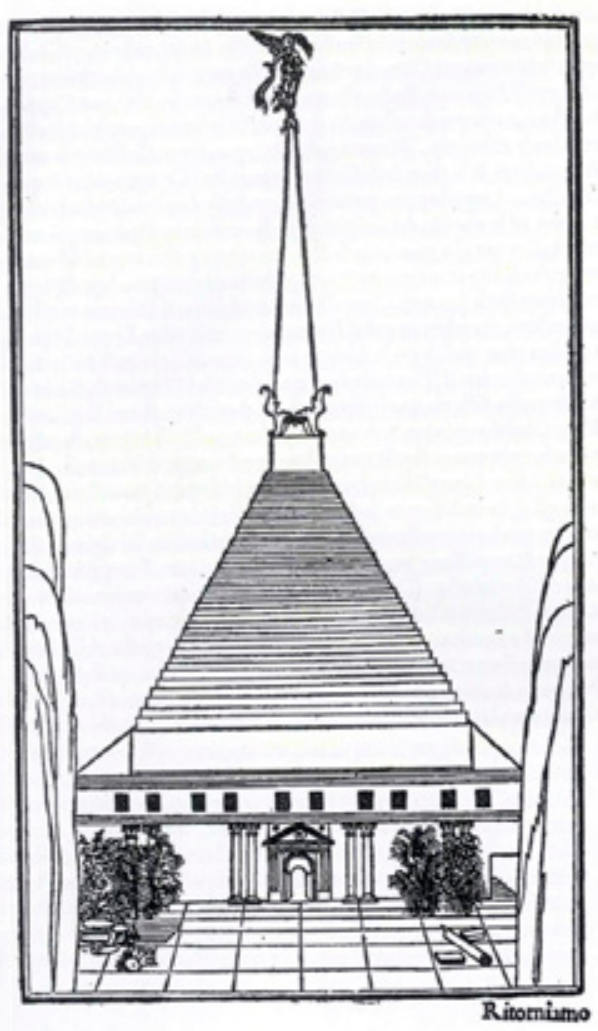

Fig. 4. Estructura piramidal. Grabado de la edición aldina de 1499, Hypnerotomachia Poliphili, 26

machia Poliphili participa en distintas categorías de sueños, entre las que se pueden distinguir: insomnium, visum y somnium. De acuerdo con Macrobio, hay ensueño (insomnium, enýpnion) "cuando una preocupación nacida de la opresión del alma, el cuerpo o la fortuna se le presenta a alguien dormido con la misma forma con que lo atormentaba despierto", poniendo, entre otros ejemplos, el de "un enamorado [que] sueña que disfruta del ser amado, o que está privado del mismo" 20 . Tomando las palabras de Artemidoro para el caso del ensueño "cuando actúan las pasiones, sucede que se perciben unas imágenes que no expresan una predicción de futuro, sino una rememoración de la realidad". ${ }^{21}$ Polifilo, insomne en la noche, expresa los avatares de su infortunado amor. Esta circunstancia amorosa tendrá un lugar destacado en su viaje onírico:

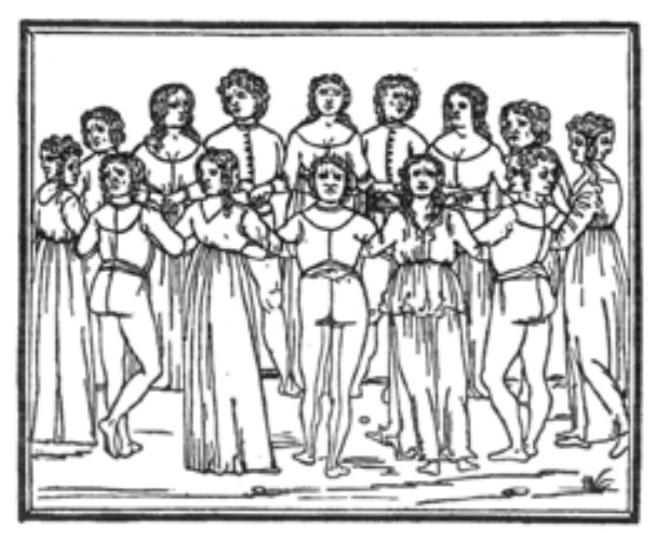

Fig. 5. Tempus. Grabado de la edición aldina de 1499, Hypnerotomachia Poliphili, 34

A solas con los altos pensamientos del amor, consumiendo insomne la larga y tediosa noche, desconsolado y suspirando a causa de mi estéril fortuna y mi adversa y mala estrella, llorando por un inoportuno y desgraciado amor...y ya cansados mis errabundos espíritus de pensar inútilmente, me nutría de un falaz y falso placer ocasionado... por un objeto no mortal, sino antes bien divino: Polia, cuya Idea venerable vive profundamente impresa en mí, intimamente grabada como mi invasora. ${ }^{22}$

Cuando Polifilo se sumerge en el sueño, el escenario cambia y Polifilo comienza su viaje:

Entonces entrecerrados los húmedos ojos con los párpados enrojecidos, fluctuando entre la áspera vida y la suave muerte, fue invadida y ocupada sin demora por el dulce sueño aquella parte que no está unida con la mente ni con los espíritus amantes y despiertos ni es partícipe de tan altas operaciones. Oh, Júpiter que resuenas desde lo alto, ¿cómo calificaré yo a esta inusitada visión, que no se encuentra en mí átomo que no tiembla al pensar en ella? ¿Feliz, admirable o aterradora? Me pareció estar en una amplia llanura... vagando por este lugar con temerosa admiración...y así mi viaje sin meta me llevó a una espesa selva, en la cual, apenas entré perdí mi camino no sé cómo. ${ }^{23}$

Al modo de Dante, perdido en una selva oscura, el ensueño de Polifilo se transforma en un infierno/ pesadilla: "sentía gran terror al pensar que, estando indefenso e ignorante, podía ser destrozado...Desorientado y despavorido, me propuse...encontrar la salida y huir de los peli- 
gros que me amenazaban". ${ }^{24}$ Esta transformación aterrorizante del paisaje se relaciona con el visum (phantasma) que Macrobio describe como un estado que ocurre cuando se está entre la vigilia y el sueño profundo: "... y sueña que ve abalanzándose sobre él o vagando siluetas que difieren de las criaturas naturales por talla o por aspecto, así como distintas perturbaciones de la realidad, placenteras o tempestuosas". ${ }^{25}$

Polifilo transita este primer visum que lo deposita en una selva oscura, para luego volver a dormirse: "De nuevo, bajo la sombra de la encina... fui preso de un gran sueño y, habiéndose esparcido por mis miembros un dulce sopor, me pareció que me dormía otra vez". ${ }^{26}$ Y luego: "Salido de la espantosa selva y del espeso bosque, y habiendo abandonado los otros lugares a que primero me referí, con el dulce sueño que se había difundido por mis fatigados y abatidos miembros, me encontré de nuevo en otro lugar, pero más agradable que el anterior". ${ }^{27}$ Es decir, el ingreso al sueño (di eminente somno oppresso), o su profundización, es señalado, primeramente, por el grabado en donde Polifilo se ve a sí mismo durmiendo bajo una encina (iterum mi parve de dormire), ${ }^{28}$ y luego, por el cambio de lugar ( $m i$ ritrovai di novo in uno piu delectabile sito assai piu che el praecedente). Por otra parte, si en los grabados anteriores Polifilo es retratado en entornos naturales (caminando en la selva oscura, arrodillado en un manantial de agua, acostado bajo la sombra de una encina), en los siguientes será dominante la presencia de entornos artificiales (monumentos, esculturas, estructuras arquitectónicas, escrituras). Podríamos señalar, en este sentido, la ya mencionada figura 2, como un espacio de transición: allí Polifilo se halla en un espacio natural, en donde la vegetación, y los animales conviven con ruinas que remiten al mundo antiguo. A partir de este momento, la antigüedad ingresa en lo que está soñando Polifilo, adoptando el lenguaje del sueño. Esta construcción onírica de la antigüedad puede explicar, en parte, como veremos en el apartado siguiente, la evocación, en términos arquitectónicos y lingüísticos, de una antigüedad plural, conformada por distintos retazos de civilizaciones antiguas.

Por otro lado, el viaje onírico de Polifilo postula el problema de la decodificación de lo visto en sueños. En el propio ámbito del sueño, Polifilo es sorprendido por imágenes que remiten a universos antiguos, a las que debe descifrar. ${ }^{29}$ Esta misma operación deberá realizarla al despertar. El somnium de carácter alegórico contiene elementos que deben ser rigurosamente interpretados para cobrar su justo valor en la realidad del que los sueña. ${ }^{30}$ Pero en el ámbito del sueño, la interpretación se presenta para Polifilo como un fenómeno difícil, y no siempre concluyente:

Encontré una antiquísima sepultura del mismo tipo que la anterior, y sobre ella otra escultura, pero de reina. Tenía levantado el brazo derecho...y con la otra mano sostenía una tablilla que se apoyaba sobre la cubierta del sarcófago; en ella estaba escrito en tres idiomas este epigrama: qvisqvis es, qvantum cvnqve libverit hvivs thesauri sume, at moneo: avfer capvt. Corpvs ne tangito. Maravillado por esta gran novedad, digna de relato, y habiendo leído los enigmas varias veces, quedé completamente ignorante y muy dudoso de su interpretación y oscuro significado. ${ }^{31}$

Esta búsqueda de interpretar las imágenes oníricas en el mismo ámbito del sueño (los jeroglíficos, pero también las diferentes escrituras, las peculiares arquitecturas y esculturas, etc.) tiene un correlato, como decíamos, en la posterior interpretación del sueño global de Polifilo. De hecho, en el texto de Colonna se expresa la separación entre el sueño y la realidad, a partir de la puesta por escrito de lo soñado, y la recurrencia a la memoria para tal propósito; en este estadio se apela también a la figura del lector:

Habiéndome arrebatado aquel placer inconcebible y aparatado de mis ojos aquel espíritu angélico y retirado de mis miembros adormilados el dulce y suave sueño, me desperté, ay de mí, amorosos lectores (amorosi lectori)...Pensad, pues, qué lívida palidez de indignación habría tenido aquel si yo hubiese disfrutado realmente (Si io realmente sentisse) de los favores voluptuosos de una muchacha tan hermosa y divina... Yo, saliendo del sueño, me desperté de repente suspirando y diciendo: "Adiós, pues, Polia". ${ }^{32}$

De acuerdo con Marco Ariani, Polifilo es "consciente de la propia, pasada bestialidad, cual auctor iniciado que recuenta, post factum, el tesoro de la sabiduría que le ha sido dolorosamente revelada en la visio in somniis". ${ }^{33}$ De hecho, el 
contenido del libro de Colonna, de acuerdo con su portada, hace referencia al carácter ilusorio de las cosas humanas: Hypnerotomachia Poliphili, ubi humana omnia non nisisomnium esse docet ("Lucha de amor en sueños de Polifilo, donde se enseña que todas las cosas humanas no son sino sueño"); así también en la segunda edición de 1545, al cuidado de los hijos de Aldo Manuzio, donde se traduce el título al italiano: La Hypnerotomachia di Polifilo, cioè pugna d'amor in sogno dov'egli mostra che tutte le cose humane non sono altre che sogno; y en la traducción francesa de 1546: "Que toutes choses terrestres ne sont que vanité".

El carácter fugaz/vano de la vida/ sueño, ${ }^{34}$ en este sentido, se encuentra también en la remisión a las estructuras arquitectónicas pertenecientes a poderosas civilizaciones antiguas que han devenido ruinas. Pero, ¿de qué Antigüedad nos habla Polifilo?

\section{Una Antigüedad híbrida}

Mencionábamos la ausencia de un sentido histórico en la obra de Colonna, una ausencia legitimada por el marco onírico en que se desenvuelve la historia de Polifilo. Esto último da lugar a la prevalencia del sincretismo y la hibridez en la representación de la antigüedad. Porque, primeramente, en la obra de Colonna no hay una sola antigüedad ni tampoco se trata de la recuperación de tiempos y espacios singulares con sus peculiaridades geográficas, culturales, y lingüísticas. En el amplio y confuso espacio del sueño del enamorado Polifilo, la antigüedad egipcia, griega y romana se condensa en edificios y lenguajes que van surgiendo, sin conformar una ciudad, un estilo, una lengua. Polifilo camina entre estos mundos antiguos, admirados e inaccesibles, por su condición fragmentaria, pero también extrañada. Se trata en efecto de la evocación de una antigüedad hibrida, conformada a partir de diversos espacios y culturas de la antigüedad, por un lado, y de la superposición de elementos antiguos y modernos, por el otro.

Esta operación ya se advierte en la lengua del texto, en el que "la base del vulgar sufre un vigoroso injerto lexical latino (...)" ${ }^{35}$ Colonna no sólo introduce palabras griegas y en mayor medida latinas sino que inventa otras aplicando -como ha estudiado Pozzi- un sufijo existente en la gramática latina a raíces también existentes en el tesoro lexical latino o vulgar, "con resultados que no pertenecieron jamás a la realidad histórica del latín o el vulgar". ${ }^{36}$ Benedetto Croce considera la lengua de Polifilo, en este sentido, un "curiosum" sin pasado y sin futuro literario y artístico. ${ }^{37}$

Si volvemos ahora a Alberti, podemos advertir cómo, en su tratado sobre arquitectura, no sólo se lamenta por el estado del texto de Vitruvio, y amonesta a seguir, en cuanto a las construcciones, las lecciones de los antiguos, sino que también las ubica en el espacio y el tiempo, ofreciendo una suerte de historia de la arquitectura. De acuerdo con Alberti, el arte de la construcción, según enseñan los monumentos antiguos, siguió un desarrollo progresivo, que tuvo su juventud en Asia, su florecimiento en Grecia y alcanzó su maduración en Italia. ${ }^{38}$ De un modo diferente, los artefactos arquitectónicos que encuentra Polifilo a su paso son superposiciones de elementos clásicos, ordenados en un conjunto que "ya no tiene nada de clásico", o ensamblados con elementos contemporáneos. En este sentido, en términos de Pozzi, para Colonna no existe una antigüedad específica, sino una antigüedad general, fuera de la geografía y de la historia, casi metafísica, de la que no está ausente una antigüedad moderna, pensada con elementos del $400 .{ }^{39}$

Este es el caso de la exuberante pirámide con un obelisco en la cima que Polifilo encuentra en primer lugar en su peregrinación onírica en busca de su amada (fig. 4). Esta monumental estructura, erigida sobre la base de la descripción de Plinio, XXXVI, 30-31, del Mausoleo de Halicarnaso y pasajes de la Roma instaurata de Flavio Biondo, es coronada por un obelisco sobre cuya cima gira la estatua de una ninfa. ${ }^{40}$ Esta ninfa, si por un lado evoca la figura de Andrónico de Cirro descripta por Vitruvio, por el otro, representa una alegoría muy difundida en los ambientes humanistas italianos, especialmente vénetos, de la diosa Fortuna. ${ }^{41}$ Lo mismo sucede con un coloso que Polifilo encuentra en este complejo arquitectónico y que llama su atención. Ingresando por su boca, Polifilo observa "todas las partes internas abiertas, como en un cuerpo humano, cada una con su denominación, escrita en tres idiomas, caldeo, griego y latín: intestinos, nervios y huesos, venas, 


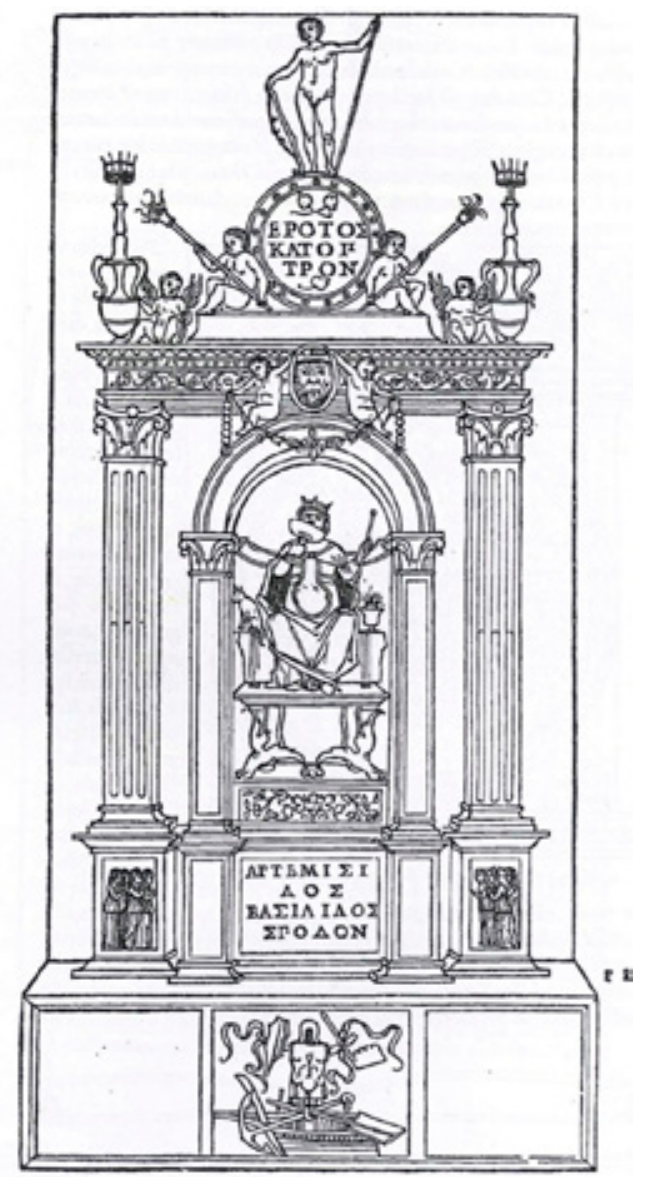

Fig. 6. Tumba de Artemisa. Grabado de la edición aldina de 1499, Hypnerotomachia Poliphili, 266

músculos y carne". ${ }^{42}$ Esta descripción anatómica nos recuerda el Tratado sobre la Pintura de Alberti (De Pictura/ Della Pittura, 1435), en donde el humanista italiano recomienda a los pintores un estudio detallado de la anatomía humana. Las recomendaciones de Alberti, los estudios de Leonardo Da Vinci, y las primeras disecciones practicadas en la época aparecen, sin embargo, evocadas en el marco de un cuerpo antiguo (el del coloso, a penas salvado de la destrucción del tiempo) cuya anotomía necesita ser nombrada en tres lenguas pertenecientes a la antigüedad: caldeo, griego y latín.

En su traslado por distintos espacios, Polifilo se adentra en tiempos pretéritos, algunos de los cuales se buscaba hacer "volver a la vida", "renacer", en el siglo XV. Pero el modo en que se superponen, entre otros, los estilos griegos, egipcios y romanos -junto con la presencia de elementos modernos- genera una sensación de extrañamiento, de la que el propio Polifilo no sale indemne. En La vida de las imágenes, F. Saxl ha señalado que en el siglo XIV veneciano se evidencian diferentes actitudes pictóricas frente al mundo antiguo, que en el caso de la ilustración lujosa de textos clásicos se pueden resumir sobre todo en dos: una en que se ignora la distancia histórica con la Antigüedad, y otra en la que ésta se transforma en distancia geográfica. En este último caso, "en su intento por representar el pasado en términos del presente lo traspone no a una época remota, sino a un lugar distante" ${ }^{43}$

Esta distancia existe también en el texto de Colonna pero a partir de la superposición de elementos de distinta naturaleza (híbridos), ${ }^{44}$ y la fusión de diferentes culturas (sincretismo). En lo que respecta a los grabados que acompañan al texto, Pericolo sostiene que prevalece la hibridación de elementos antiguos y modernos propia del ambiente artístico veneciano, del que participan el o los ilustradores de la Hypnerotomachia. De acuerdo con este autor, de un modo diferente a la bipolaridad planteada por Warburg para el arte florentino del tardío siglo $X V^{45}$ no se trata de reconstrucciones ni de elaboraciones sobre antiguos modelos, sino de compuestos en que antigüedad y modernidad se interconectan entre sí sin fundirse, produciendo un efecto de extrañamiento: el ejemplo que utiliza es el de la tumba de Artemisa (fig. 6), en donde hay un intento de armonizar modernidad y antigüedad por parte del ilustrador que remodeló un esquema iconográfico religioso (la Virgen en majestad) en una fórmula pagana: "Colonna y su ilustrador preservaron la estructura básica de un retablo veneciano, adaptándola a un monumento funerario antiguo". ${ }^{46}$ Imágenes y texto trabajan en este sentido combinando construcciones antiguas y modernas ubicadas en un espacio y tiempo que es otro e irreal.

Esta peculiar representación de la antigüedad encuentra un correlato en la pregunta que Polifilo hace una y otra vez en el texto, en función de su extravío espacial y espiritual. De hecho, Polifilo, 
inmerso en un sueño del que nace la visión que relata, como hemos ya señalado, al igual que Dante, comienza su recorrido perdido en una selva oscura: "Y así mi viaje sin meta me llevó a una espesa selva, en la cual, apenas entré, perdí mi camino no sé cómo". ${ }^{47}$ Polifilo manifiesta en otras oportunidades también su ignorancia sobre el espacio en el que se encuentra: “ ¿dónde has dejado una cosa tan amable? -preguntan unas ninfas en referencia a su amada Polia- No lo sé-contesta Polifilo-, como tampoco sé dónde estoy". ${ }^{48}$

\section{Conclusiones}

Polifilo se adormece, angustiado, con la Idea de Polia en su mente. En el primer sueño, atado aún a los sinsabores diurnos, su visum lo llevará a entornos donde la naturaleza se torna feroz y amenazante. Polifilo da un paso más allá cuando su sueño se profundiza y se transforma en somnium. En el somnium del peregrino, el mundo antiguo desplaza el entorno natural. Ciertamente, la aegritudo amori se vuelve fortuna amori: Polifilo logra encontrar a su amada Polia, que lo acompañará en el resto de su viaje onírico. Este hallazgo, sin embargo, no tiene un correlato con el sendero visual que recorren, cuyo caso emblemático es el de las ruinas del Cementerio de los enamorados. Reza, de hecho, el título extendido que las cosas humanas no son sino sueño. De allí que tengan reunión en esta lucha de amor el carácter fugaz del sueño/vida y de las estructuras arquitectónicas que remiten a civilizaciones antiguas. Los fragmentos que de éstas han quedado son expresión del pasado, objetos dignos de contemplación. Porque Polifilo es, además del amante de Polia, un enamorado de las antiquarie opere.

Este peregrino se enfrenta a la tarea de decodificar una antigüedad híbrida, construida sobre la base de sincretismos diversos. Desde este punto de vista, la reconstrucción históricoarqueológica de la antigüedad cede lugar a la aglomeración de imágenes oníricas que remiten a un pasado transfigurado. La memoria se vuelve para recordar y apuntar lo soñado, dando nacimiento a la novela cuyo acompañamiento visual se torna indispensable para comprender el contenido onírico, construido sobre la base de un tenue hilo narrativo.

Esta ausencia de linealidad está sobre todo presente en la representación de la antigüedad. Como Dante, o Petrarca, en su ascensión al Monte Ventoso, en el caso de Polifilo el horizonte espacial alude al horizonte espiritual. Pero la inquietud de Polifilo ante la ausencia de referencias espaciales adquiere otra dimensión. La antigüedad es un espacio híbrido y en cierta medida indescifrable, dominado por la invención, antes que por el redescubrimiento. 


\section{NOTAS}

1 Thomas Greene, "Imitation and Anachronism", en The Light in Troy. Imitation and Discovery in Renaissance Poetry (New Haven and London: Yale University Press, 1982), 28-53.

2 Citaremos a lo largo de este trabajo la edición y traducción de Pilar Pedraza. Francesco Colonna, Sueño de Polifilo (Barcelona: El Acantilado, 1999). Pondremos a continuación las citas de la reproducción de la edición aldina de 1499. Francesco Colonna, Hypnerotomachia Poliphili (Milano: Adelphi, 1998).

${ }^{3}$ En el acróstico que forman las letras iniciales de cada uno de los 38 capítulos de la Hypnerotomachia se lee Poliam Frater Franciscus columna peramavit. Leonardo Grasso, su patrocinador, revela en la dedicatoria al Duque de Urbino, que había llegado a sus manos "una obra nueva y admirable de Polifilo", "carente de padre" a la que dice haber cuidado y transmitido a sus expensas. Colonna, Sueño de Polifilo, 65. Sobre la identidad de Francesco Colonna ver: María Teresa Casella, Biografía (Padova: Antenore, 1959); Marco Ariani e Mino Gabriele, "L'autore del Polifilo", en Hypnerotomachia Poliphili (Milano: Adelphi, 1998), LXII- XCIII. La identidad del autor de la Hypnerotomachia no ha dejado de suscitar controversias. Frente a la hipótesis que concibe a Francesco Colonna como un fraile véneto, figuran, entre otras, la de Maurizo Calvesi, La Pugna d'amore in sogno di Francesco Colonna romano (Roma: Lithos, 1996) y la de Emanuela Kretzulesco- Quaranta, Les Jardins du songe. Poliphile e la Mystique de la Renaissance (Paris: Les belles lettres, 1986), quien imagina una obra compuesta por múltiples manos, entre las cuales se encontraría la del propio Leon Battista Alberti.

${ }^{4}$ De hecho, el Sueño de Polifilo es en un libro en gran medida célebre por los grabados que ilustran sus dos ediciones aldinas de 1499 y 1545. En cuanto a la génesis de las xilografías seguimos la hipótesis de Ariani y Gabriele, quienes sostienen que estas fueron elaboradas por un taller veneciano, donde trabajaban y colaboraban distintos dibujantes y grabadores, activo por lo menos entre 1490 y 1499. Los grabados de la Hypnerotomachia Poliphili son entonces el fruto culto de un arte de taller, heterogéneo en su formación artística. Marco Ariani e Mino Gabriele, "Le illustrazioni", en Hypnerotomachia Poliphili (Milano: Adelphi, 1998), XCV.

${ }^{5}$ Colonna, Sueño de Polifilo, 92. "Apparendo pur opera et structura antiquaria...Mirando et considerando tuto el solido et la crassitudine questa fragmentata et semiruta structura...Quivi dunque tanta nobile columnatione io trovai de ogni figuratione, liniamento, et materia...Di statue ingente fracture truncate molti degli aerati et exacti membri...et quasi infiniti altri fragmenti de scalptura nobili, de cognito quali integri fusseron, totalmente privi et quasi redacti al primo rudimento". Colonna, Hypnerotomachia..., 22.

6 "Restaban vetera rerum exempla templis theatrisque mandata, ex quibus tanquam ex optimis professoribus multa discerentur: eadem non sine lachrymis videbam in dies deleri; et qui forte per haec tempora aedificarent, novis ineptiarum \|deliramentis potius quam probatissimis laudatissimorum operum rationibus delectari; quibus ex rebus futurum negabat nemo, quin brevi haec pars, ut ita loquar, vitae et cognitionis penitus esset interitura. Idcirco haec cum ita essent, non poteram non facere, quin de commentandis his rebus et saepe et diu cogitarem". Leon Battista Alberti, De re aedificatoria, a cura di Giovanni Orlandi (Milano: II Polifilo, 1966), VI, I.

7 Peter, Burke, El sentido del pasado en el Renacimiento (Madrid: Akal, 2016), 39.

8 Anthony Blunt, "The hypnerotomachia Poliphili in 17th Century France", Journal of the Warburg Institute, 1 , n. 2 (1937): 117- 137.

${ }^{9}$ Colonna, Sueño..., 91. "Electo Signo de victoria", "Quivi al gli ochii mei uno iocundissimo Palmeto se appraesento cum le foglie di cultrato mucrone ad tanta utilitate ad gli aegyptii", Colonna, Hypnerotomachia..., 21.

${ }^{10}$ Colonna, Sueño...., 399-400. "Dique la insigne parimenti et io di imensa dulcedine suffulti, et in sincero amore corroborati...ad uno veterrimo aedificio pervenissemo...per vorace tempo et per putre antiquitate et per negligentia al humida terra collapso", Colonna, Hypnerotomachia..., 236.

${ }^{11}$ La ninfa que gira sobre el obelisco tiene unas alas en la espalda, en una de sus manos una cornucopia (símbolo de la abundancia y la prosperidad), con la otra se aferra el pecho. El mechón de pelo situado en la frente y la nuca calva, alude a la ocassio propicia.

${ }^{12}$ Colonna, Sueño...,110-111. "...alcune figure di homini et damigelle chorigianti cum due facie per uno. Quella dinanti ridibonda, la posteriora lachrymosa...Sotto la quale Hemiale figura vidi tale parola inscripta. TEMPUS", Colonna, Hypnerotomachia..., 34.

${ }^{13}$ Colonna, Sueño..., 409. "Poliphile di tutti amantissimo mio gia non son ignara che le antiquarie opere ad te sumamente piaceno di vedere. Adunque commodamente potes tu in questo intervallo, che nui al signore cupidine aspetiamo ire licentemente, queste aede deserte, \& dalla edace \& exoleta vetustate collapse (...) a tuo solacio mirare, \& gli fragmenti nobili rimasti di venerato speculare", Colonna, Hypnerotomachia..., 242.

${ }^{14}$ Roland, Mortier, La poétique des ruines en France (Genève: Librairie Droz, 1974), 33-34.

${ }^{15}$ Sinesio de Cirene, "Sobre los Sueños", en Himnos. Tratados (Madrid: Gredos, 1993), $154 \mathrm{~d}$.

${ }^{16}$ Escogimos para ello una constelación de textos que circulaban en el Renacimiento en los que se estudia la cuestión onírica. Un manuscrito del 400 de Sinesio de Cirene, con el comentario de Niceforo Gregora, se encontraba en el convento veneciano de Santi Giovanni e Paolo, donde se ha ubicado a Colonna como dominico. Mino Gabriele, "Introduzione", Hypnerotomachia..., $X X X$.

${ }^{17}$ Macrobio, Comentario al Sueño de Escipión de Cicerón (Madrid: Gredos, 2006), 137.

Platón en su República distingue los sueños que responden a deseos reprimidos en la vigilia, de aquellos que tienen un contenido de verdad: " $¿ Y$ a qué deseos te refieres? -preguntó. /A los que surgen durante el sueño -respondí-, cuando duerme esa parte del 
alma que es razonable, tranquila y hecha para mandar, y la parte bestial y feroz...se insubordina...Bien sabes que en esos momentos esa parte del alma a todo se atreve, como si se hubiera desligado y liberado de toda vergüenza y de toda sensatez....A mi juicio, en cambio...cuando se apacigua el elemento irascible y no se acuesta con el ánimo excitado contra alguno sino que, después de haber aquietado estas dos partes de su alma y estimulado la tercera, en la que reside el buen sentido, se abandona por fin al descanso, bien sabes que en esas condiciones es cuando mejor alcanza la verdad y cuando menos pueden turbarlo las visiones ilegitimas de los sueños" (Rep. 571 c- d, 572 a- b). En el Timeo: "Cuando se cierras [los párpados], se bloquea la potencia del fuego interior que disminuye y suaviza los movimientos interiores y cuando éstos se han suavizado, nace la calma, y cuando la calma es mucha, el que duerme tiene pocos sueños. Pero cuando quedan algunos movimientos de mayor envergadura, según sea su cualidad y los lugares en los que quedan, así es el tipo y la cantidad de las copias interiores que producen y que, al despertar, recordamos como imágenes exteriores" (Tim. 45-46). Aristóteles, en Acerca de los ensueños, sostiene que "los movimientos producidos por las sensaciones, tanto por las del exterior como por las procedentes del propio cuerpo, no sólo existen cuando se está despierto, sino también cuando sobreviene esa afección que se llama sueño, e incluso predominantemente entonces" (461, a).

${ }^{18}$ Macrobio, Comentario..., 140.

${ }^{19}$ Sinesio de Cirene, "Sobre los sueños", 149 b.

${ }^{20}$ Macrobio, Comentario..., 138.

${ }^{21}$ Artemidoro, La interpretación de los sueños (Madrid: Gredos, 1989), 7.

${ }^{22}$ Colonna, Sueño..., 78-79. "Dique negli alti cogitamenti d'amore solo relicto, la longa et taediosa nocte insomne consumando, per la mia sterile fortuna et adversatrice et iniqua stella tutto sconsolato, et sospiroso, per importuno et non prospero amore...e gia fessi gli vaghi spiriti de pensare inutilmente, et pabulato d'uno fallace et fincto piacere... d'uno non mortale, ma piu praesto amore divo obiecto di Polia, La cui veneranda Idea in me profundamente impressa, et piu intimamente insculpta occupatrice vive", Colonna, Hypnerotomachia..., 12.

${ }^{23}$ Colonna, Sueño..., 78-81. "Hora li madidi ochii uno pocho tra le rubente palpebre rachiusi, Sencia dimorare vita acerba, et suave morte. Fue invasa et quella parte occupata et da uno dolce somno oppressa, laquale cum la mente et cum gli amanti et pervigili spiriti non sta unita ne participe ad si alte operatione. O lupiter altitonante, foelice o mirabile o terrífica, diro io questa inusitata visione, che in me non la trova atomo che non tremi et ardi excogitandola. Ad me parve de essere in una spatiosa planitie....Nel quale loco io cum timida admiratione discolo...Et cusi dirrimpecto d'una solta silva ridrizai el mio ignorato viagio", Colonna, Hypnerotomachia..., 12-13.

${ }^{24}$ Colonna, Sueño..., 81-82. "Et percio cum máximo terriculo dubitava, di essere sencia alcuna defensa, et sencia avederme dilaniato...dubitando ispagurito, Ivi proposi...piu non dimorare et de trovare exito et evadere gli occorrenti pericoli", Colonna, Hypnerotomachia..., 14.

${ }^{25}$ Macrobio, Comentario...,139-
${ }^{26}$ Colonna, Sueño..., 89. "Di nuovo sotto di questa umbra quercunea...i'fui di eminente somno oppresso \&sparso per gli membri il dolce sopore, iterum mi parve de dormiré", Colonna, Hypnerotomachia..., 19.

${ }^{27}$ Colonna, Sueño..., 90- 91. "La spaventevole silva et constipato Nemore evaso \& gli primi altri lochi per el dolce somno che se havea per le fesse \& prosternate membre difusso relicti, mi ritrovai di novo in uno piu delectabile sito assai piu che el praecedente", Colonna, Hypnerotomachia..., 20.

${ }^{28}$ En sus notas a la Hypnerotomachia Poliphili, señalan Ariani y Gabriele que el tema del sueño profundo obedece a la exigencia de dar al sueño de Polifilo credibilidad oracular y mistérica: significados que se conjugan con el simbolismo de la encina bajo la cual se duerme: "se trata de un topos onírico y literario" que remite al Sueño de Escipción de Cicerón, y que se vuelve a encontrar tanto en el Roman de la Rose como en Dante o en Boccaccio. Marco Ariani e Mino Gabriele, "Commento", 545.

${ }^{29}$ Destaca en este sentido la presencia de "jeroglíficos". Anna Klimkiewicz hace una lectura de la obra de Colonna centrada en el interés hacia el oriente, entre el 1400 y 1500. Anna Klimkiewicz, "Cultura sincretica dell'Hypnerotomachia Poliphili di Francesco Colonna", Cuadernos de Filología italiana, 21 (2014): 181-194.

Giehlow es quien ha estudiado, en los inicios del siglo $X X$, la relación entre los jeroglíficos egipcios y los humanistas, señalando que en el temprano Renacimiento existía la creencia que cierta sabiduría podía obtenerse de los jeroglíficos; de allí los intentos de imitarlos. En 1419, C. de Buondelmonti adquiere el manuscrito que contiene al final dos libros de Hierogliphica de Horapollo. El Hierogliphica, comprado por C. de Buondelmonti, fue llevado a Florencia y luego ubicado en la biblioteca Medicea. Karl Giehlow, The humanist interpretation of Hieroglyphs in the Allegorical Studies of the Renaissance: with a focus on the Triumphal Arch of Maximilian I (Boston: Brill, 2015 [1915]).

${ }^{30}$ De acuerdo con Polizzi: "la lectura del relato impone la exigencia perpetua de un desciframiento en el cual Polifilo mismo da el ejemplo interrogándose sobre el sentido de las múltiples inscripciones y "jeroglíficos". En este sentido, "la alegoría deviene enigma". Gilles, Polizzi, "Le Songe de Poliphile: renovation ou metamorphose du genre litteraire", en Le Songe à la Renaissance: Colloque International de Cannes, editado por François Charpentier (Université de Saint Etienne: Association d'étude sur l'humanisme, la Réfore et la Renaissance, 1990), 94.

${ }^{31}$ Colonna, Sueño..., 118-119. "Et in questo lato ancora una medesima factura di veterrima sepultura trovai. Et la statua supra stante di tutto, quale I'altra, Se non che era regina. La quale sublevato il dextro bracio cum lindice signava la parte retro le sue spalle et cum I'altro teniva una tabella ritinuta cum il coperto et cum la mano sua indivisa. Nella quale etiam inscripto era tale epigramma in tri idioma (...). Di tanta 
novitate digna di relato mirabondo et degli aenigmati praelegendoli saepiculi, dil tutto io restai ignaro, et dilla interpretatione et sophismo significato molto ambiguo". Colonna, Hypnerotomachia..., 39-40.

${ }^{32}$ Colonna, Sueño..., 722-723. "Tanto inopinabile delectamento surrepto et dagli ochii mei summoto quel spirito angelico, Et subtracto fora dagli somnosi membri il dolce et suave dormiré evigilantime, In questo punctulo, Ome Heu me amorosi lectori...Cogitate dunque quale livore livido, alhora ello harebbe, Si io realmente sentisse perfruendo gli proprii et voluptici dilecti, de cusi formosa et diva damicella...sospirando emerso et absoluto dal dolce somno repentuscule melucubrai dicendo. Vale ergo Polia", Colonna, Hypnerotomachia..., 465.

En "Sobre los sueños", declara Sinesio de Sirene que: "Que cada uno tenga a sí mismo como materia de este arte, que grabe en su memoria en qué hechos se ha visto envuelto, cuándo y con qué tipo de visiones previas. Sería también prudente poner por escrito nuestras visiones durante la vela o el sueño". Sinesio de Sirene, "Sobre los sueños", 152d- 153a.

${ }^{33}$ Marco Ariani, "Introduzione", XXXV.

${ }^{34}$ Perrier sostiene que en el siglo $\mathrm{XVI}$, el pensamiento, sentimiento y uso del sueño se ubica entre dos polos: el "songe vrai", en el que el sueño puede ser "revelación, inspiración, acceso al saber" y el "songe- mensonge", es decir, el sueño como ilusión fugaz. Simone Perrier, "La problematique du songe a la Renaissance: la norme et les marges", en Le Songe à la Renaissance: Colloque International de Cannes (Université de Saint- Etienne: Association d'etude sur I'humanisme, la Réforme et la Renaissance, 1990), 11.

${ }^{35}$ Giorgio, Agamben, El final del poema: estudios de poética y literatura. (Buenos Aires: Adriana Hidalgo, 2016), 96-97.

${ }^{36}$ Pozzi e Casella, Francesco Colonna. Biografia e opere. II, 103.

${ }^{37}$ Benedetto, Croce, "Studii sulla Letteratura Cinquecentesca", Quaderni della "Critica" 4, no.17-18 (1950), 49.

${ }^{38}$ Alberti, De re aedificatoria, VI, III.
${ }^{39}$ Giovanni Pozzi e María Teresa Casella, Francesco Colonna. Biografia e opere. II, 65.

${ }^{40}$ Sobre el Mausoleo de Halicarnaso como fuente arqueológica- literaria de la gran estructura piramidal, señala Huelsen: "Prescindiendo del obelis$\mathrm{co}$, el dibujo polifiliano no es sino un intento de reconstrucción de uno de los monumentos griegos más distinguidos, conocido por los humanistas del Quattrocento sólo merced a la literatura antigua (...): o sea, el Mausoleo de Halicarnaso, considerado ya en la Antigüedad como una de las siete maravillas del mundo, y descripto con gran precisión por Plinio el joven en el libro XXXV de la Naturalis Historia (§§ 30-31)". Christian Huelsen, Le illustrazioni della Hypnerotomachia Polifili e la antichità di Roma (Firenze: Leo S. Olschki, 1910), 9. En su comentario a la Hypnerotomachia Poliphili, sostienen Ariani y Gabriele que Colonna se inspiró en el pasaje de Plinio sólo para el armazón geométrico-arquitectónico, pero que otra fuente pudo haber inspirado a Colonna: la Meta Romuli. Ariani e Gabriele, "Commento", 552. Pozzi, por su parte, sostiene que Colonna retoma un párrafo de F. Biondo en su Roma instaurata "en el que con manifiesto error de identificación es descripto el Mausoleo de Augusto". Pozzi e Casella, Francesco Colonna. Biografia e opere. II, 58.

${ }^{41}$ Pozzi, Francesco Colonna. Biografia e opere II, 63.

${ }^{42}$ Colonna, Sueño...,113. "io mirai tutte le parte intimamente, quale in uno humano corpo pervie. Ed ad qualunque mirai in scalpto in tre idiomati, Chaldeo, Graeco, et Latino, di quella parte la sua appellatione, che in ciascuno naturale corpo vedesse intestini, nervi, et ossa, vene, musculi, et pulpamento", Colonna, Hypnerotomachia..., 36.

${ }^{43}$ Fritz, Saxl, La vida las imágenes. Estudios iconográficos sobre el arte occidental (Madrid: Alianza, 1989), 141.

${ }^{44}$ En este marco, podemos ubicar a los "centauros y sirenas lexicales" a las que se refiere Pozzi, en alusión a la extraña lengua de Colonna, construida sobre la base del vulgar y con una importante contribución latina, dando, como ya hemos advertido, resultados "que no pertenecieron jamás a la realidad histórica del latín o del vulgar". Pozzi e Casella, Francesco Colonna. Biografia e opere, 103. En su libro El Renacimiento europeo, Peter Burke también habla de "sincretismo" e "hibridación" para referir las interacciones entre mundos culturales diversos: "No hay términos que no sean problemáticos o discutibles en este campo intelectual, pero en el resto de este estudio se hará un esfuerzo por reservar el término "sincretismo" para los intentos conscientes de armonizar elementos de las diferentes culturas (como Ficino hizo en el caso del platonismo y el cristianismo), dejando el término "hibridación" como un concepto más vago para referirse a una variedad de interacciones entre las culturas". Peter Burke, El Renacimiento europeo (Barcelona: Crítica, 2000), 18. En este caso no hay dos cosmovisiones puestas en diálogo, sino que lo que sobresale es la ausencia de una diferenciación entre identidades culturales y epocales diversas que da lugar a conjuntos híbridos y extrañados. Otra es la cuestión de las diferentes fuentes, paganas y cristianas, que conviven en la Hypnerotomachia Poliphili: Vitruvio, Ovidio, Apuleyo, Plinio y, en una medida equivalente, Dante, Petrarca, Boccaccio, Alberti..

${ }^{45}$ De acuerdo con Warburg, "Conjugar oposiciones, en apariencia irreductiblemente extrañas, entre las ropas flamencas de los pastores y los trajes imperiales (...) entre Dios y la Fortuna (...) son fruto de una polaridad orgánica, de las oscilaciones propias del hombre culto del Renacimiento que persigue su reconciliación en una época de enérgica metamorfosis de la autoconciencia". Aby Warburg, El renacimiento del paganismo. Aportaciones a la historia cultural del Renacimiento europeo (Madrid: Alianza, 2005 [1932]), 199.

${ }^{46}$ Lorenzo Pericolo, "Heterotopia in the Renaissance: Modern Hybrids as Antiques in Bramante, Cima da Conegliano, and The Hypnerotomachia Poliphili", Getty Research Journal, n. 1 (2009), 9. Los modelos venecianos contemporáneos a los que alude Pericolo son el del Tríptico de los Frari de G. Bellini (1488, aprox.) y el de Santa Veneranda entronizada, de Lazzaro 
Bastiani (1470- 1475), que dan cuenta de cómo el ilustrador de la Hypnerotomachia se basó en prototipos de su ambiente contemporáneo. Veáse también la decodificación de los elementos ornamentales del sepulcro en Arani e Gabrielle "Commento", Hypnerotomachia Poliphili, 929-931.

${ }^{47}$ Colonna, Sueño..., 81."Et cusi dirrimpecto d'una folta silva ridrizai el mio ignorato viagio", Colonna, Hypnerotomachia..., 13.

${ }^{48}$ Colonna, Sueño..., 186. "Dove l'ai tu (tanto cosa dilecta) abandonata? Io non intendo, et dove io ancora me sia non so", Colonna, Hypnerotomachia..., 84. 


\section{REFERENCIAS}

Agamben, Giorgio. 2016 [1996]. El final del poema: estudios de poética y literatura. Buenos Aires: Adriana Hidalgo.

Alberti. 1966. L'architettura [De re aedificatoria]. Ed. Giovanni Orlandi. Milano: II Polifilo.

Ariani, Marco, e Mino Gabriele. 1998. "Introduzione" e "Commento." En Hypnerotomachia Poliphili. Tomo secondo. IX-CIX; 4851168. Milano: Adelphi.

Aristóteles. 1987. Acerca de la Generación y la Corrupción. Tratados breves de Historia Natural. Ed. Ernesto La Croce y Alberto Bernabé Pajares. Madrid: Gredos.

Artemidoro. 1989. La Interpretación de los Sueños. Ed. Elisa Ruiz García. Madrid: Gredos.

Blunt, Anthony. 1937. "The Hypnerotomachia Poliphili in 17th Century France." Journal of the Warburg Institute 1-2 (October): 117- 137. https://doi.org/10.2307/750050

Burke, Peter. 2000. El Renacimiento europeo. Barcelona: Crítica.

Burke, Peter. 2016 [1969]. El sentido del pasado en el Renacimiento. Madrid: Akal.

Casella, M. Teresa, e Giovanni Pozzi. 1959. Francesco Colonna. Biografia e opere. I. Padova: Antenore.

Casella, M. Teresa, e Giovanni Pozzi. 1959. Francesco Colonna. Biografia e opere. II. Padova: Antenore.

Colonna. 1998. Hypnerotomachia Poliphili. Tomo primo: riproduzione dell'edizione aldina del 1499. Ed. Marco Ariani e Mino Gabriele.

Colonna. 1999. Sueño de Polífilo. Ed. Pilar Pedraza.

Croce, Benedetto. 1950. "Studii sulla Letteratura Cinquecentesca." Quaderni della "Critica" 4 (17-18, Novembre): 47- 54.

Giehlow, Karl.2015 [1915]. The humanist interpretation of Hieroglyphs in the Allegorical Studies of de Renaissance: with a focus on the Triumphal Arch of Maximilian I. Boston: Brill. https://doi.org/10.1086/686340

Greene, Thomas. 1982. "Imitation and Anachronism." In The Light in Troy. Imitation and
Discovery in Renaissance Poetry. New Haven and London: Yale University Press. https://doi. org/10.2307/2862019

Huelsen, Christian. 1910. Le illustrazioni deIla Hypnerotomachia Polifili e la antichità di Roma. Firenze: Leo S. Olschki.

Klimkiewicz, Anna. 2014. "Cultura sincretica dell'Hypnerotomachia Poliphili di Francesco Colonna." Cuadernos de Filología italiana 21: 181-194.

Macrobio. 2006. Comentarios al "Sueño de Escipión" de Cicerón. Ed. Fernando Navarro Antolín. Madrid: Gredos.

Mortier, Roland. 1974. La poétique des ruines en France. Ses origines, ses variations de la Renaissance à Victor Hugo. Genève: Librairie Droz.

Pericolo, Lorenzo. 2009. "Heterotopia in the Renaissance: Modern Hybrids as Antiques in Bramante, Cima da Conegliano, and The Hypnerotomachia Poliphili." Getty Research Journal 1: 1- 16.

Platón. 1998. República. Tr. Antonio Camarero. Buenos Aires: Eudeba.

Platón. 2007. Diálogos VI. Filebo-Timeo-CritiasCartas. Ed. M. Ángeles Durán, Francisco Lisi, Juan Zaragoza y Pilar Gómez Cardó. Madrid: Gredos.

Polizzi, Gilles. 1990. "Le Songe de Poliphile: renovation ou metamorphose du genre litteraire." En Le Songe à la Renaissance: Colloque International de Cannes, edition François Charpentier, 85-96. Université de Saint Etienne: Association d'étude sur l'humanisme, la Réforme et la Renaissance.

Saxl, Fritz. 1989 [1957]. La vida de las imágenes. Estudios iconográficos sobre el arte occidental. Madrid: Alianza.

Sinesio de Cirene. 1993. Himnos. Tratados. Ed. Francisco García Romero. Madrid: Gredos.

Warburg, Aby. 2005 [1932]. El renacimiento del paganismo. Aportaciones a la historia cultural del Renacimiento europeo. Madrid: Alianza. 
